\title{
Activation of Mitochondrial Unfolded Protein Response in SHSY5Y Expressing APP Cells and APP/PS1 Mice
}

\author{
Yang Shen ${ }^{1}$, Mao Ding ${ }^{1}$, Zhaohong Xie ${ }^{2}$, Xiangtian Liu ${ }^{1}$, Hui Yang ${ }^{2}$, Suqin Jin ${ }^{2}$, Shunliang \\ $\mathrm{Xu}^{2}$, Zhengyu Zhu ${ }^{2}$, Yun Wang ${ }^{2}$, Dewei Wang ${ }^{2}$, Linlin $\mathrm{Xu}^{2}$, Xiaoyan Zhou ${ }^{2}$, Ping Wang ${ }^{2 *}$ \\ and Jianzhong $B i^{2 *}$
}

${ }^{1}$ Medicine School, Shandong University, Jinan, China, ${ }^{2}$ Department of Neurology Medicine, Second Hospital of Shandong University, Jinan, China

\section{OPEN ACCESS}

Edited by:

Miriam L. Greenberg,

Wayne State University,

United States

Reviewed by:

Xing Guo,

Nanjing Medical University, China Jinsoo Seo,

Daegu Gyeongbuk Institute of Science and Technology (DG/ST), South Korea

*Correspondence: Ping Wang wping0108@163.com Jianzhong Bi

bjz@sdu.edu.cn

Received: 03 September 2019 Accepted: 09 December 2019 Published: 08 January 2020

Citation:

Shen Y, Ding $M$, Xie Z, Liu X, Yang $H_{\text {, }}$ Jin $S, X u S$, Zhu Z, Wang $Y$, Wang $D$, $X u$ L, Zhou $X$, Wang $P$ and $B i J$ (2020) Activation of Mitochondrial Unfolded Protein Response in SHSY5Y Expressing APP Cells and APP/PS1 Mice. Front. Cell. Neurosci. 13:568. doi: 10.3389/fncel.2019.00568
Alzheimer disease (AD) is the most common form of dementia. Amyloid $\beta$-peptide $(A B)$ deposition is a major neuropathologic feature of $A D$. When unfolded or misfolded proteins accumulate in mitochondria, the unfolded protein responses (UPRmt) is initiated. Numerous lines of evidence show that AD pathogenesis involves mitochondrial dysfunction. However little is known about whether the UPRmt is engaged in the process of AD development. In this study, we investigated the UPRmt in mouse and cell models of AD. We found that UPRmt was activated in the brain of 3 and 9 months old APP/PS1 mice, and in the SHSY5Y cells after exposure to $A \beta_{25-35}, A \beta_{25-35}$ triggered UPRmt in SHSY5Y cells could be attenuated upon administration of simvastatin or siRNA for HMGCS-1 to inhibit the mevalonate pathway, and or upon knocking down Serine palmitoyltransferase long chain subunit 1 (SPTLC-1) to lower sphingolipid biosynthesis. We observed that inhibition of UPRmt aggravated cytotoxic effects of $A \beta_{25-35}$ in SHSY5Y cells. Our research suggests that the UPRmt activation and two pathways necessary for this response, and further provides evidence for the cytoprotective effect of UPRmt during the $A D$ process.

Keywords: Alzheimer disease, UPRmt, mevalonate pathway, sphingolipid biosynthesis pathway, simvastatin

\section{INTRODUCTION}

Alzheimer disease $(\mathrm{AD})$ is the most common form of dementia in the elderly population and characterized by progressive deterioration of cognitive and functional abilities (Pleckaityte, 2010). Extracellular amyloid plaques, consisting of polymers of amyloid- $\beta$ peptides (A $\beta$ ), and intracellular neurofibrillary tangles, formed mainly by hyperphosphorylated protein tau,

Abbreviations: AD, Alzheimer disease; A $\beta$, Amyloid $\beta$-peptide; APP, Amyloid Precursor Protein; UPRmt, Mitochondrial unfolded protein response; HtrA2/Omi, High-temperature requirement protein A2/Omi; Hsp60, Heat shock protein 60; CLPP, Caseinolytic protease P; LONP1, Lon peptidase 1; HMG-CoA, 3-hydroxy-3-methyl-glutaryl-CoA; HMGCS-1, Human hydroxymethylglutaryl-CoA synthase 1; SPT, serine palmitoyltransferase; SPTLC-1, Serine palmitoyltransferase long chain subunit 1; CCK8, Cell Counting Kit 8; BCA, Bicinchoninic acid; PVDF, Polyvinylidene difluoride; ROS, Reactive oxygen species; WT, Wildtype; IMS, Intermembrane space. 
are the main neuropathology of AD (Swerdlow, 2007). Diverse lines of evidence support that oligomeric species of $A \beta$ are the causative agent of $\mathrm{AD}$. $\mathrm{A} \beta$ is a general term to define $38-43$ amino acid peptides generated from the sequential cleavage of the Amyloid Precursor Protein (APP) by $\beta$ - and $\gamma$-secretase (Da Costa Dias et al., 2011). While $A \beta_{1-40}$ and $A \beta_{1-42}$ are the main forms of $A \beta$ peptides deposited in extracellular amyloid plaques, $A \beta_{1-42}$ is more prone to aggregation than $A \beta_{1-40}$ (Selkoe, 2001). The APPsw/PS1dE9 double transgenic mouse line is widely used for investigating the pathogenic mechanisms of $\mathrm{AD}$ for its property of effective production of $A \beta_{1-42}$ (Borchelt et al., 1996). $A \beta_{25-35}$, a synthetic peptide of 11 amino acids, retains physical and biological properties of full-length $A \beta$ and is often employed for generating acute AD models (Kang et al., 1987; Harkany et al., 2000).

Mitochondria are crucial cellular organelles essential for numerous cellular functions including energy homeostasis, metabolism, and apoptosis (Wang and Youle, 2009; Blackstone, 2015). Disruption of mitochondrial protein folding homeostasis results in the accumulation of unfolded or misfolded proteins and induce a mitochondria-to-nuclear signal transduction pathway termed the unfolded protein responses (UPRmt), through which upregulated expression of mitochondrial molecular chaperones and proteases is induced to re-establish protein homeostasis (Zhao et al., 2002; Tatsuta and Langer, 2008; Papa and Germain, 2011; Pellegrino et al., 2013). The accumulation of misfolded proteins has been described as a pathological hallmark of numerous neurodegenerative diseases, including $\mathrm{AD}$, Parkinson's disease, Huntington's disease and amyotrophic lateral sclerosis (Skovronsky et al., 2006). Although $A \beta$ accumulation in mitochondria has long been known to exist in brain of $\mathrm{AD}$ patients as well as TgAPP mice (Lustbader et al., 2004; Caspersen et al., 2005; Manczak et al., 2006), little is known about whether the UPRmt is involved in the pathogenesis of AD. A couple of lines of evidence suggest a role for the UPRmt in the development of $\mathrm{AD}$ pathology. Levels of HtrA2/Omi (high temperature requirement protein $\mathrm{A} 2 / \mathrm{Omi}$ ), a protein operating in the process of UPRmt, are reduced in AD frontal cortex, yet its enzymatic activity is significantly increased in the same samples (Westerlund et al., 2011). In addition, there exists increased transcription and translation of UPRmt associated genes in the brain of familial and sporadic $\mathrm{AD}$ patients, e.g., upregulation of $h s p d 1$ (HSP60) and clpp (CLPP mitochondrial protease) genes, but not lon1p1 (the LONP1 mitochondrial protease; Beck et al., 2016).

The mevalonate pathway produces isoprenoids, which are vital for diverse cellular functions (Goldstein and Brown, 1990), and has been demonstrated to be required for the activation of the UPRmt in C. elegans. 3-hydroxy-3-methyl-glutaryl-CoA (HMG-CoA) reductase is the rate-limiting enzyme in the mevalonate pathway; statins inhibit this enzyme to lower plasma cholesterol levels. Upon treatment with statins, C. elegans fail to sense mitochondrial damage and to activate the UPRmt (Liu et al., 2014; Ranji et al., 2014; Oks et al., 2018). Inactivation of the hmgs-1 gene, which encodes HMG-CoA synthase, renders C. elegans to lose the capability to respond to mitochondrial dysfunction and to inhibit antimycin-induced UPRmt induction
(Liu et al., 2014). Human hydroxymethylglutaryl-CoA synthase 1 (HMGCS-1) is the ortholog of C. elegans HMGS-1 protein and mediates the first committed step of the mevalonate pathway (Sapir et al., 2014). We hypothesize that the mevalonate pathway participates in the activation of UPRmt in the process of $\mathrm{AD}$ development.

Sphingolipids are a class of lipids that are highly enriched in the central nervous system and play important functions in membrane structure, signal transduction, and a variety of biological processes (Spiegel and Merrill, 1996; Mielke and Haughey, 2012). Alterations in the sphingolipids metabolism are thought to be concerned with $\mathrm{AD}$ development. The rate-limiting enzyme of sphingolipid biosynthesis is serine palmitoyltransferase (SPT), a multiprotein complex catalyzing the first step of sphingolipid de novo synthesis pathway (Hanada, 2003; Hornemann et al., 2007). Serine palmitoyltransferase long chain subunit 1 (SPTLC-1) is one subunit of SPT (Hanada, 2003; Hornemann et al., 2006). Inactivation of the sptl-1 gene causes $C$. elegans unresponsive to mitochondrial dysfunction and inhibits antimycin-induced UPRmt induction (Liu et al., 2014). Hence, we speculate that the sphingolipids metabolism pathway also takes part in the UPRmt activation during the $\mathrm{AD}$ process.

In this study, we examined UPRmt related proteins levels in APP/PS1 mouse and SHSY5Y cells treated with A $\beta$ to determine if the UPRmt contributes to AD pathogenesis. We exploited chemical drugs and small interfering RNAs to manipulate the mevalonate and sphingolipids biogenesis pathways, using drug or siRNA to evidence the involvement of these pathways in activating UPRmt.

\section{MATERIALS AND METHODS}

\section{Reagents and Preparation of Drugs}

Amyloid $\beta$ protein fragment $25-35\left(\mathrm{~A} \beta_{25-35} \mathrm{~A} 4559\right)$ was purchased from Sigma-Aldrich. The $\mathrm{A} \beta_{25-35}$ was first dissolved in tri-distilled water to $1 \mathrm{mM}$ and then incubated at $37^{\circ} \mathrm{C}$ for 7 days. The solution was aliquoted and stored at $-20^{\circ} \mathrm{C}$, until use. Simvastatin was purchased from MedChem Express (MCE, HY-17502).

\section{Antibodies}

Antibodies specific for APP (126732), HtrA2/Omi (75982), $\beta$ Actin (11132), CLPP (124822), GAPDH (9485), respectively, were purchased from Abcam. Antibodies for LONP1 (15440), Hsp60 (15282), HMGCS-1 (17643), SPTLC-1 (15376) were obtained from Proteintech.

\section{Animals and Tissues}

All procedures regarding the use of animals were conducted according to the guidelines and approved by the Ethical Committee for Animal Experiments of Shandong University. We used the APPsw/PS1dE9 double transgenic mice at the age of 3 and 9 months, age-matched C57BL/6 mice as a control. All mice were male ( $n=10$ per group) and purchased from Beijing HFK Bioscience Co., Limited (Beijing, China). When reaching the age of 3 and 9 months, mice were anesthetized by $10 \%$ of chloral hydrate and then sacrificed by cervical dislocation 
and decapitation. Fresh hippocampal tissues were harvested and stored at $-80^{\circ} \mathrm{C}$ until use for studies. All applicable Shandong University and the ethical committee of the Second Hospital of Shandong University guidelines for the care and use of animals were followed.

\section{Cell Culture and Treatments}

The human neuroblastoma cell line SHSY5Y was obtained from the Cell Resource Center, IBMS, CAMS/PUMC. Cells were cultured in RPMI-1640 medium (HyClone) supplemented with $10 \%$ fetal bovine serum (Gibco) at $37^{\circ} \mathrm{C}$ and $5 \% \mathrm{CO}_{2}$. Cells at $50-70 \%$ confluence were treated with $\mathrm{A} \beta_{25-35}$, and or simvastatin. Control cells were cultured under normal conditions.

\section{Cell Viability Assay}

Cells were seeded into 96-well plates. After culturing for $24 \mathrm{~h}$, cells were treated with simvastatin or SPTLC-1 siRNA for $48 \mathrm{~h}$ and then treated with $A \beta_{25-35}$ for another $4 \mathrm{~h}$. After treatments, cells in each well were incubated with Cell Counting Kit 8 (CCK8) solution (MedCjemExpress) at $37^{\circ} \mathrm{C}$ for $3 \mathrm{~h}$ and then used for measuring the absorbance at $450 \mathrm{~nm}$ with a microplate reader (Thermo, Multiskan MK3, USA). Experiments were repeated for at least three times.

\section{SDS-PAGE and Western Blotting}

The Hippocampal tissues and cells after treatments were homogenized in RIPA lysis buffer (Beyotime Biotechnology). Cell debris and nuclei were discarded after a centrifugation at $4^{\circ} \mathrm{C} 12,000 \mathrm{~g}$ for $10 \mathrm{~min}$. The supernatants were collected and the protein concentration was measured with the bicinchoninic acid (BCA) method. After SDS-PAGE, proteins were blotted onto polyvinylidene difluoride (PVDF) membranes. Blots were blocked in 5\% skimmed milk powder in TBST and incubated with corresponding primary antibodies at $4^{\circ} \mathrm{C}$ for $12-16 \mathrm{~h}$. After extensive washes in TBST, blots were incubated with HRP conjugated secondary antibodies for $1-2 \mathrm{~h}$ at room temperature. Proteins were detected with ECL (enhanced chemiluminescence) regents.

\section{Transmission Electron Microscopy}

Cells were collected and fixed in pre-cooled glutaraldehyde for at least $2 \mathrm{~h}$. After postfixation in osmic acid solutions and sequential dehydration, cells were embedded in EPON812 resins. Ultrathin sections were cut and collected onto grids, stained with uranium and lead citrate, and observed under a JEM-1200EX electron microscope (JEOL, Tokyo, Japan).

\section{Measurement of ROS Levels}

Intracellular reactive oxygen species (ROS) levels were detected using DCFH-DA (Beyotime, S0033), which is non-fluorescent and generates fluorescent signals after being oxidized into DCF in the presence of intracellular ROS. The day before experiments, cells were planted into 12-well plates and cultured for $24 \mathrm{~h}$. After brief washes in PBS, cells were incubated with DCFH$\mathrm{DA}(10 \mu \mathrm{mol} / \mathrm{L})$ at $37^{\circ} \mathrm{C}$ for $20 \mathrm{~min}$, then washed three times with RPMI-1640 medium. Fluorescence images were captured using a fluorescence microscope (OLYMPUS BX43) at excitation and emission wavelengths of 488 and $525 \mathrm{~nm}$. The amount of ROS was quantified with the use of a fluorescence microplate reader. All experiments were repeated for at least three times.

\section{Transfection of siRNAs}

SHSY5Y cells were transfected with target siRNAs using INTERFRERin (Polyplus-transfection Inc., New York, NY, USA). Corresponding scrambled siRNAs were used as controls. After transfection with siRNA for $48 \mathrm{~h}$, cells were treated with or without $A \beta$ as indicated and then collected cells for examinations.

\section{Statistical Analysis}

All data were expressed as mean \pm SEM. One-way analysis of variance (ANOVA) or Two-tailed student's $t$-test was used for determining statistical significance. Data were analyzed using SPSS 20.0 (SPSS Inc., Chicago, IL, USA). A p-value of less than 0.05 was considered to be statistically significant.

\section{RESULTS}

\section{A $\beta$ Activates UPRmt Responses}

To determine whether $A \beta_{25-35}$ treatment can cause the above UPRmt reactions, we treated SHSY5Y cells with different concentrations of $A \beta_{25-35}$ for $24 \mathrm{~h}$ and then examined expression levels of UPRmt related proteins. We found that expression levels of mitochondrial matrix chaperone Hsp60, AAA proteases CLPP and the IMS-localized quality control protease HtrA2/Omi were increased after exposure to $2.5,10$ and $20 \mu \mathrm{M} \mathrm{A} \beta_{25-35}$ for $24 \mathrm{~h}$. Levels of Hsp60 and CLPP, but not HtrA2/Omi, were also significantly increased in cells treated with $5 \mu \mathrm{M} \mathrm{A} \beta_{25-35}$ for $24 \mathrm{~h}$. Under the same conditions, the upregulation of the LONP1 protein was detected only in cells exposed to 10 and $20 \mu \mathrm{M} \mathrm{A} \beta_{25-35}$ (Figure 1A). We then investigated whether treatment with $20 \mu \mathrm{M} \mathrm{A} \beta_{25-35}$ for a shorter time period could sufficiently activate UPRmt. Our data showed that the expression levels of all the four proteins mentioned above were elevated in SHSY5Y cells after exposure to $20 \mu \mathrm{M} \mathrm{A} \beta_{25-35}$ for $4 \mathrm{~h}$ (Figure 1B).

To determine whether the UPRmt occurred in the brain of APPsw/PS1dE9 double transgenic mice, we first conducted biochemical studies to compare expression levels of UPRmt related proteins in hippocampi of 3 and 9 months old wildtype (WT) and APPsw/PS1dE9 transgenic mice, levels of APP in hippocampal lysates of both 3 and 9 months old transgenic mice was significantly increased compared with those in hippocampal lysates of age-matched WT mice (Figure 1C). Western blot analysis revealed that expression levels of Hsp60, CLPP and HtrA2/Omi were significantly increased in the hippocampus of 3 months old APPsw/PS1dE9 transgenic mice relative to those of 3 months old WT mice (Figure 1C). Under the same conditions, levels of the LONP1 protein were comparable in hippocampi of 3 months old WT and transgenic mice. However, levels of HtrA2/Omi and CLPP in hippocampal lysates of 9 months old transgenic mice were not different from those in hippocampal lysates of 9 months old WT mice, 


\section{A}

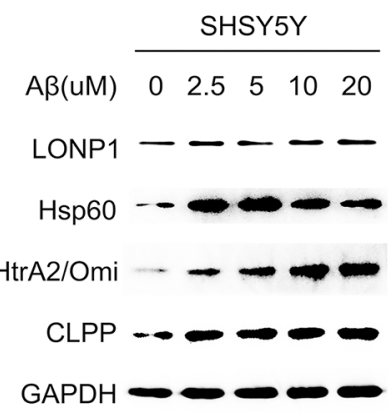

B

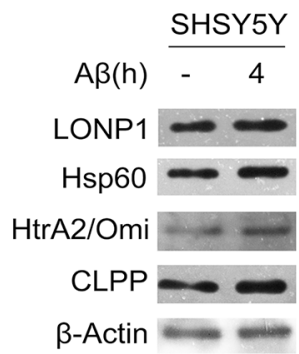

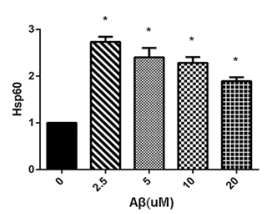
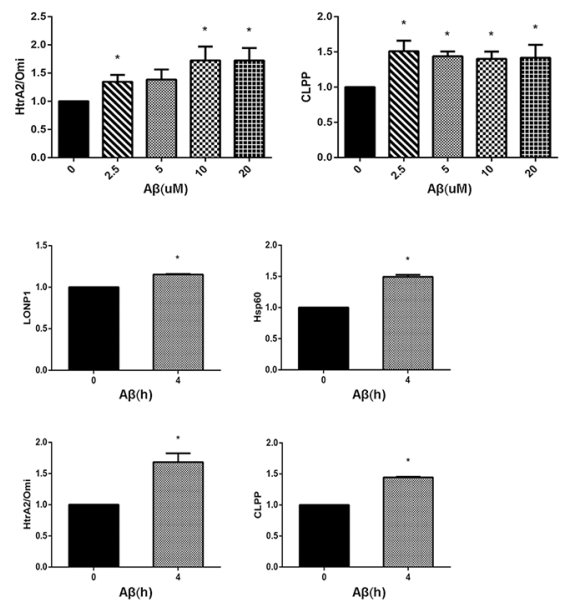

C

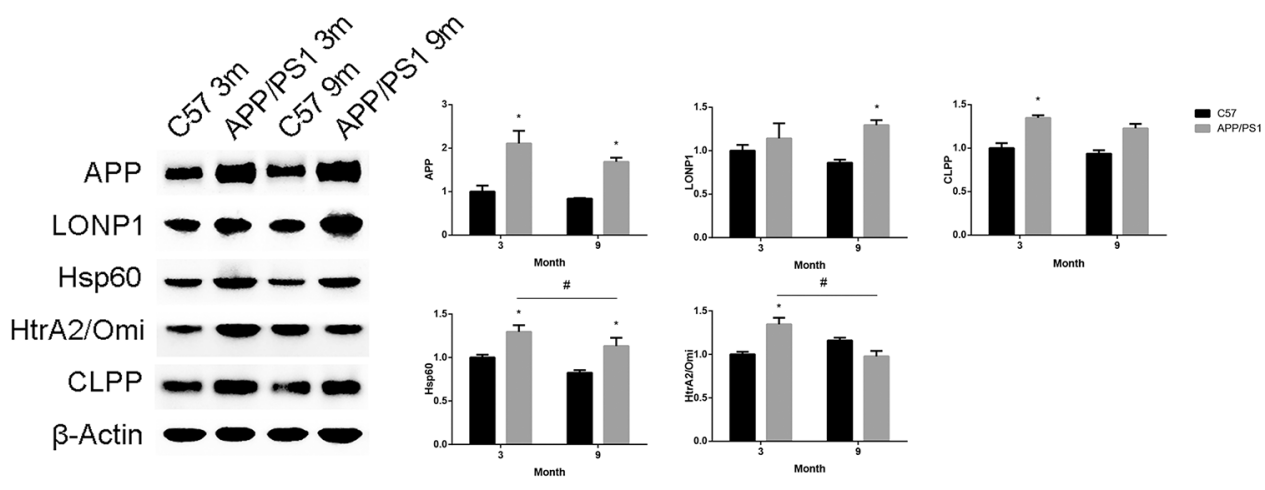

FIGURE 1 | UPRmt response activated during the Alzheimer disease (AD) process in vitro and in vivo. (A) Western blot analysis of UPRmt related proteins level in SHSY5Y cells treated with different concentrations of $A \beta_{25-35}$ for $24 \mathrm{~h}$ and quantification, GAPDH served as the internal control. (B) Western blot analysis of UPRmt related proteins level in SHSY5Y cells treated with $20 \mu \mathrm{M} \mathrm{A} \beta_{25-35}$ for $4 \mathrm{~h}$, quantification and $\beta$-Actin served as the internal control. The data are mean \pm SEM $(n=3$, ${ }^{*} p<0.05$ vs. control group). (C) Western blot analysis of UPRmt related proteins level in C57 and APP/PS1 transgenic mice at 3 and 9 months, quantification and $\beta$-Actin served as the internal control. The data are mean $\pm \operatorname{SEM}\left(n=10,{ }^{*} p<0.05\right.$ vs. age-matched C57 mice group, $\left.{ }^{\#} p<0.05\right)$.

whereas levels of LONP1 and Hsp60 in the hippocampus of 9 months old transgenic mice were increased compared with those of age-matched control mice (Figure 1C). We also found that the expression levels of Hsp60 and HtrA2/Omi were significantly decreased in the hippocampus of 9 months old APPsw/PS1dE9 transgenic mice relative to those of 3 months old transgenic mice. Taken together, our in vitro and in vivo data suggest that UPRmt occurs in the process of $\mathrm{AD}$ pathological development.

\section{The Mevalonate Pathway is Involved in $A \beta_{25-35}$ Evoked UPRmt in SHSY5Y Cells}

There was upregulated expression of HMGCS-1, an enzyme that mediates the first committed step of the mevalonate pathway, in cells treated with $20 \mu \mathrm{M} \mathrm{A} \beta_{25-35}$ for $4 \mathrm{~h}$ (Figure 2A).
This observation led us to speculate that the mevalonate pathway might be involved in the activation of the UPRmt in cells treated with $A \beta$. To test this possibility, we treated SHSY5Y cells with HMGCS-1 siRNAs or with simvastatin to manipulate the mevalonate pathway. The expression level of HMGCS-1 was decreased in cells transfected with HMGCS-1 siRNAs for $48 \mathrm{~h}$, compared with the HMGCS-1 level in cells transfected with scrambled siRNA. As shown in Figure 2B, in the absence of $A \beta$, there was no statistically significant difference in UPRmt related protein levels between cells transfected with scrambled siRNA and target siRNA. However, we found that after transfected with HMGCS-1 siRNAs, the expression levels of LONP1, Hsp60, HtrA2/Omi, and CLPP were significantly down-regulated in cells treated with $20 \mu \mathrm{M} \mathrm{A} \beta$ for $4 \mathrm{~h}$ (Figure 2C). We then detected whether simvastatin treatment 
A

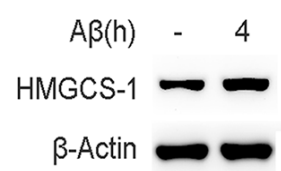

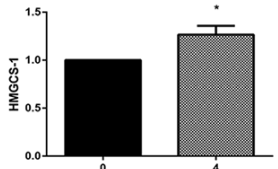

B

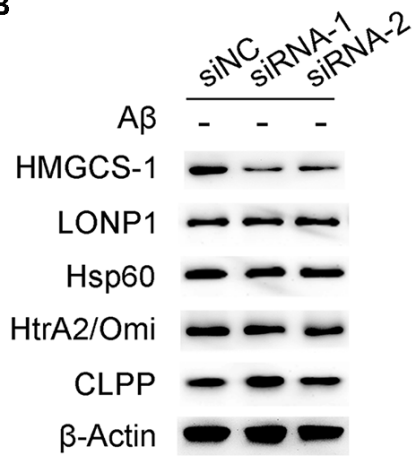

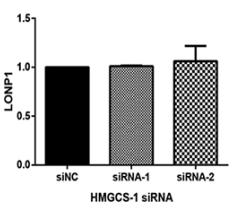
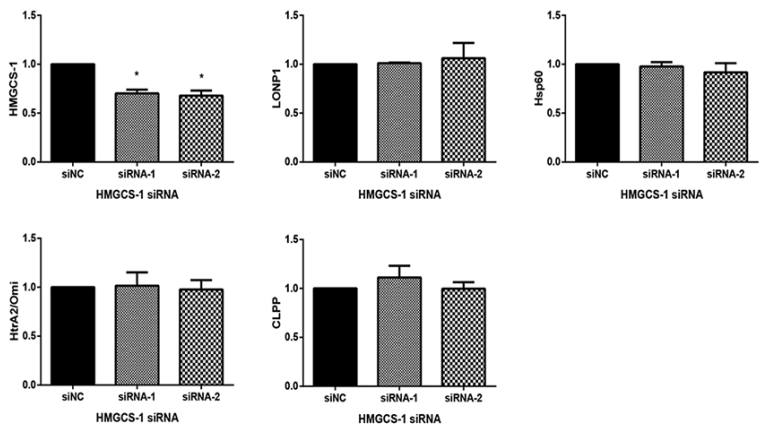

C

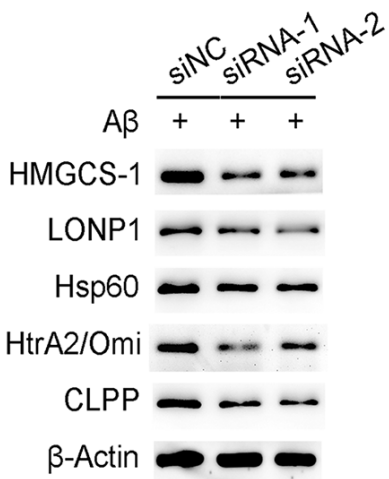

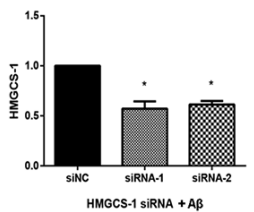
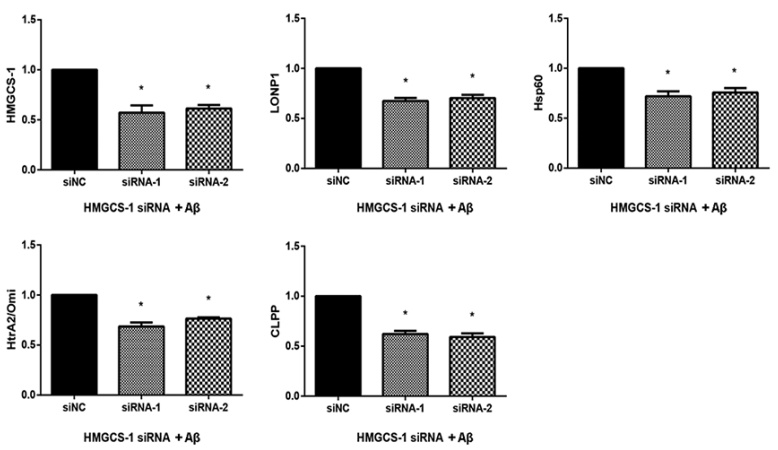

D
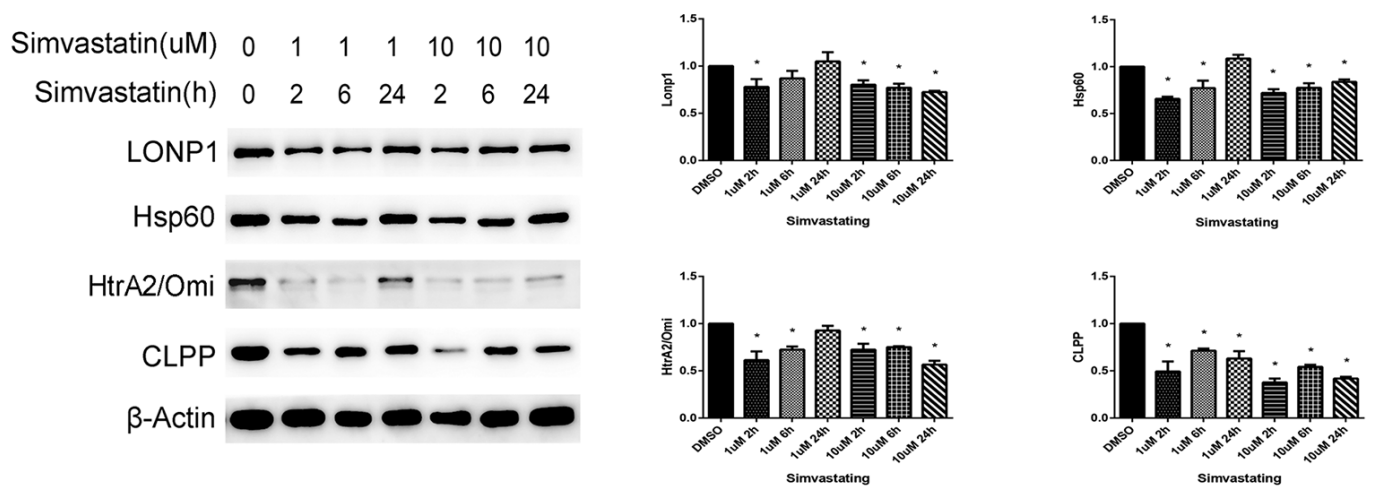

FIGURE 2 | Inhibition of the mevalonate pathway by HMGCS-1 siRNAs or simvastatin reduces the UPRmt reaction induced by A $\beta_{25-35}$ in SHSY5Y cells.

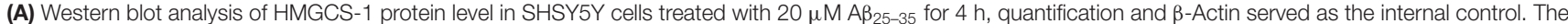
data are mean \pm SEM ( $n=3,{ }^{*} p<0.05$ vs. control group). (B) Western blot analysis of HMGCS-1 and UPRmt related proteins level in SHSY $5 Y$ cells transfected with scramble or HMGCS-1 siRNAs for $48 \mathrm{~h}$, quantification and $\beta$-Actin served as the internal control. The data are mean \pm SEM ( $n=3$, ${ }^{*} p<0.05$ vs. siNC group). (C) Western blot analysis of HMGCS-1 and UPRmt related proteins level in SHSY5Y cells transfected with scramble or HMGCS-1 siRNAs for 48 h and $20 \mu \mathrm{M}$ $\mathrm{A} \beta_{25-35}$ treatment for $4 \mathrm{~h}$, quantification and $\beta$-Actin served as the internal control. The data are mean $\pm \mathrm{SEM}\left(n=3,{ }^{*} p<0.05\right.$ vs. siNC group). (D) After treated with $1 \mu \mathrm{M}$ and $10 \mu \mathrm{M}$ simvastatin for different time courses, we detected the UPRmt related proteins level in SHSY5Y cell with $20 \mu \mathrm{M}$ A $\beta_{25-35}$ by western blot analysis, $\beta$-Actin served as the internal control. The data are mean $\pm \operatorname{SEM}\left(n=3,{ }^{*} p<0.05\right.$ vs. DMSO group). 
could similarly dampen the effect of $A \beta_{25-35}$ on the activation of the UPRmt reaction. We first treated cells with or without $1 \mu \mathrm{M}$ or $10 \mu \mathrm{M}$ of simvastatin for $2 \mathrm{~h}, 6 \mathrm{~h}$, and $24 \mathrm{~h}$, and then added $20 \mu \mathrm{M} \mathrm{A} \beta_{25-35}$ to cell culture media to treat cells for $4 \mathrm{~h}$. The data in Figure 2D showed that except for the treatment with $1 \mu \mathrm{M}$ simvastatin for $24 \mathrm{~h}$, all other treatment conditions significantly decreased the expression of Hsp60 and HtrA2/Omi compared with the vehicle treatment. Compared with those in vehicle-treated cells, levels of CLPP in all of the simvastatin treatment conditions were decreased. Except for the group that $1 \mu \mathrm{M}$ simvastatin treatment for $6 \mathrm{~h}$ and $24 \mathrm{~h}$, expression of Lonp1 protein in other groups were decreased compared with control (Figure 2D). From the above, we can see that inhibition of the mevalonate pathway induced by HMGCS-1 siRNAs or simvastatin reduce the expression of UPRmt related proteins in SHSY5Y cells treated with $\mathrm{A} \beta_{25-35}$.

\section{Simvastatin Treatments Change the Cell Morphology and Mitochondrial Structure, Increase the Intracellular ROS Level and Aggravate the Cytotoxic Effect of $A \beta_{25-35}$ in SHSY5Y Cells}

During experiments, we observed a phenomenon with a microscope, that $24 \mathrm{~h}$ treatment of $10 \mu \mathrm{M}$ simvastatin changed the cell's morphology and promoted the apoptosis of cells treated with $A \beta_{25-35}$ (Figure 3A). The electron micrograph also showed that the simvastatin treatment aggravates the morphological changes of mitochondrial, such as mitochondrial vacuolation, disorganization, and reduction of the crista (Figure 3B). We further tested the intracellular ROS level by use of the ROS-sensitive fluorescent probe DCFH-DA, the fluorescence images and the amount of ROS showed that simvastatin treatment aggravated the increased intracellular ROS level induced by $A \beta_{25-35}$ (Figure $3 \mathrm{C}$ ). The cells viability was tested with the CCK8 method. As shown in Figure 3D, pretreatment with $10 \mu \mathrm{M}$ simvastatin for $24 \mathrm{~h}$ aggravated the decrease of cell viability induced by $A \beta_{25-35}$.

\section{The Sphingolipid Biosynthesis Pathway is Involved in $A \beta_{25-35}$ Evoked UPRmt in SHSY5Y Cells}

In a previous study, RNAi mediated inactivation of the sptl-1 gene, which encodes SPT, disrupted response to mitochondrial dysfunction in $C$. elegans. To detect whether it happens in SHSY5Y cells treated with $A \beta_{25-35}$, we used the SPTLC- 1 siRNAs to hinder sphingolipid biosynthesis. As shown in Figure 4A, treatment of cells with $20 \mu \mathrm{M} \mathrm{A} \beta_{25-35}$ for $4 \mathrm{~h}$ led to the upregulation of SPTLC-1. The expression level of SPTLC-1 was decreased in cells transfected with SPTLC-1 siRNAs for $48 \mathrm{~h}$, compared with the SPTLC-1 level in cells transfected with scrambled siRNA. As shown in Figure 4B, in the absence of $A \beta$, there was no statistically significant difference in UPRmt related protein levels between cells transfected with scrambled siRNA and target siRNA. However, we found that after transfected with SPTLC-1 siRNAs, the protein levels of LONP1, Hsp60,
HtrA2/Omi and CLPP were both decreased in cells treated with $20 \mu \mathrm{M} \mathrm{A} \beta$ for $4 \mathrm{~h}$ (Figure 4C). Thus, the Inhibition of the sphingolipid biosynthesis pathway by SPTLC-1 siRNAs decreases the UPRmt related proteins level in SHSY5Y cells treated with $A \beta_{25-35}$.

\section{Inhibition of the Sphingolipid Biosynthesis Pathway by SPTLC-1 siRNAs Changes the Mitochondrial Structure, Increases the Intracellular ROS Level and Aggravates the Cytotoxic Effect of $A \beta_{25-35}$ in SHSY5Y Cells}

To determine whether inhibition of the sphingolipid biosynthesis pathway can cause a similar effect like simvastatin, we tested the cells' mitochondrial structure, intracellular ROS level, and cell viability after transfected with SPTLC-1 siRNAs. As shown in Figure 5A, the Inhibition of the sphingolipid biosynthesis pathway by SPTLC-1 siRNAs aggravated the abnormalities in mitochondrial morphology, such as mitochondrial vacuolation and reduction of the crista. The fluorescence images and the amount of ROS also showed that $A \beta_{25-35}$ increased the intracellular ROS level and SPTLC-1 siRNAs transfection aggravated the ROS accumulation (Figure 5B). The cells viability tested by the CCK8 method also showed that SPTLC-1 siRNAs transfection aggravated the decrease of cell viability induced by $\mathrm{A} \beta_{25-35}$ (Figure 5C).

\section{DISCUSSION}

This study showed that the UPRmt was activated in SHSY5Y cells with $\mathrm{A} \beta_{25-35}$ treatment and APPsw/PS1dE9 transgenic mice, and inhibition of the mevalonate and sphingolipid biosynthesis pathway disrupted the activation of UPRmt in SHSY5Y cells induced by $A \beta_{25-35}$. We further found that inhibition of these two pathways through simvastatin and SPTLC-1 siRNAs aggravated the mitochondrial injury, ROS accumulation and the decrease of cell viability in SHSY5Y cells induced by $A \beta_{25-35}$.

Numerous diseases are associated with UPRmt, including spastic paraplegia, Parkinson's disease, Friedreich's ataxia and cancer (Haynes and Ron, 2010). Most reports about the unfolded protein response in $\mathrm{AD}$ were focused on the endoplasmic reticulum, but studies about the UPRmt were little except for the research mentioned above (Beck et al., 2016). So we tested the UPRmt reaction in cell and mice models of $\mathrm{AD}$ in this research. In cell models, all of the four UPRmt related proteins were upregulated in SHSY5Y cells treated with $10 \mu \mathrm{M}$ or $20 \mu \mathrm{MA} \beta_{25-35}$ for $24 \mathrm{~h}$. As shown in results, the UPRmt related proteins Hsp60, HtrA2/Omi and CLPP were upregulated in APPsw/PS1dE9 transgenic mice at 3 months, while to 9 months, Hsp60 and LONP1 proteins were increased compared with age-matched WT mice. Thus, we conclude that the UPRmt response was activated during the $\mathrm{AD}$ process in vitro and in vivo.

Among the UPRmt related proteins, LONP1 as a mitochondrial matrix protease, maintain the mitochondrial homeostasis by degrading misfolded or oxidized polypeptides. As shown in Figure 1A, the LONP1 protein level was unchanged 
A

Control

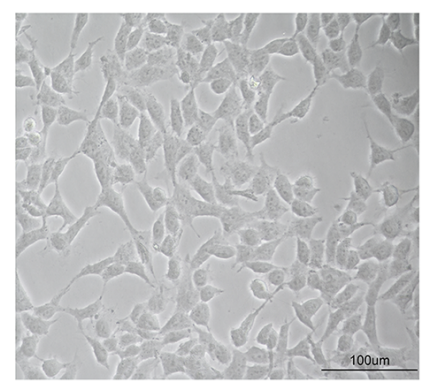

B

Control

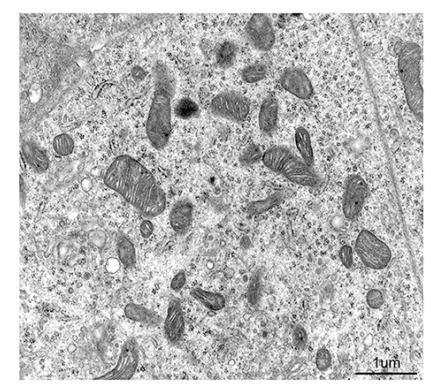

C

Control
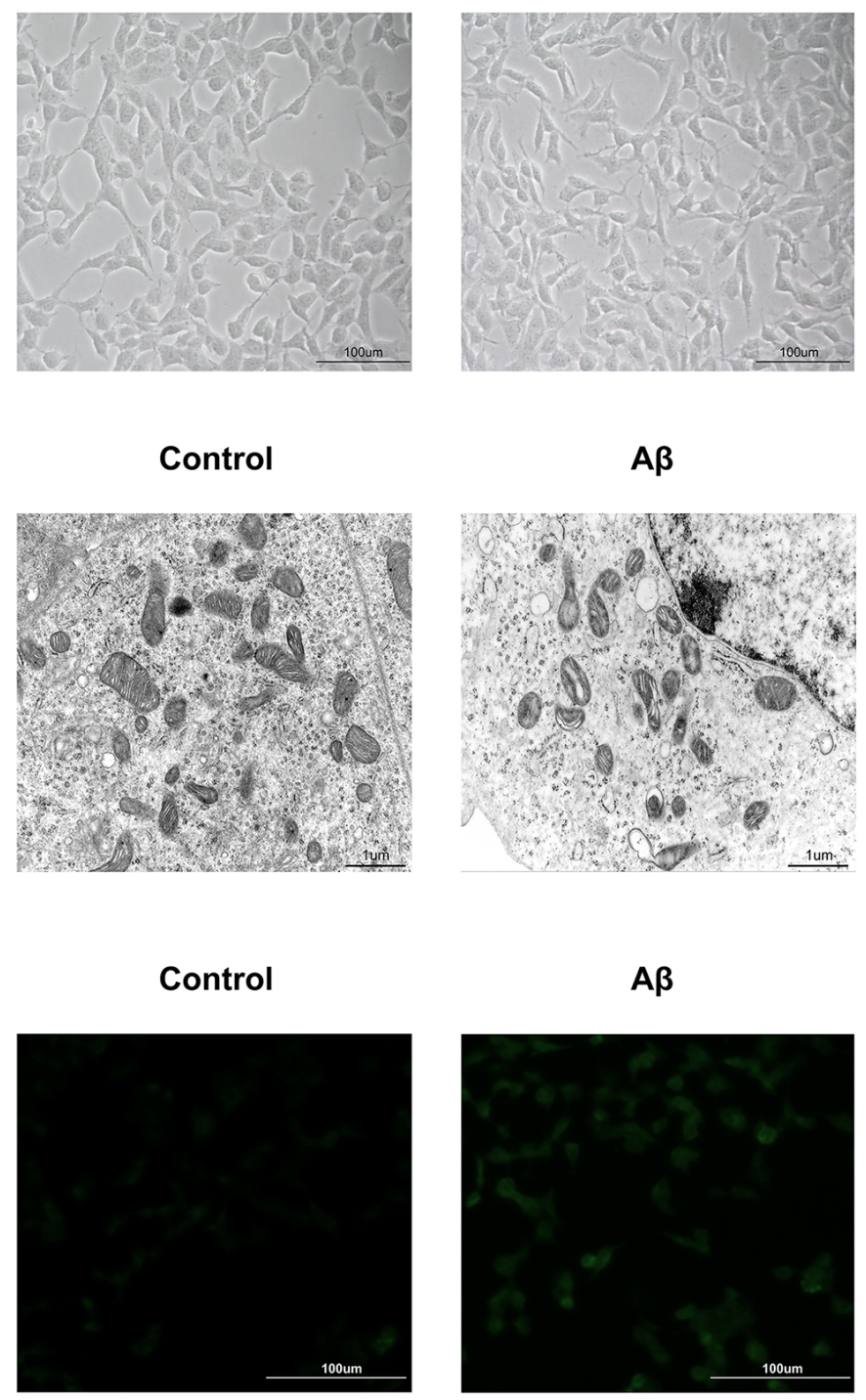

$A \beta$

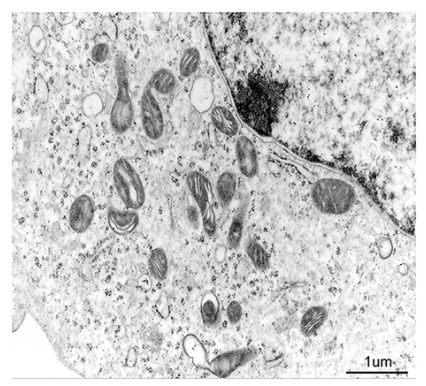

$A \beta+S i m v a s t a t i n$

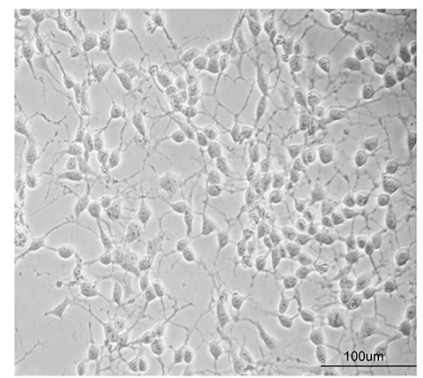

$A \beta+$ Simvastatin

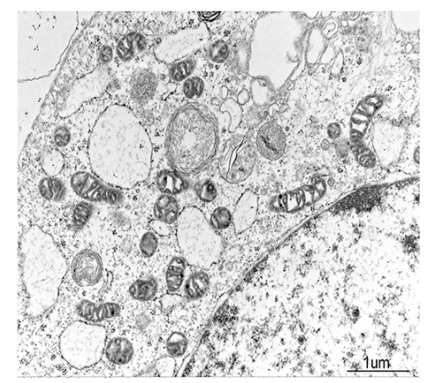

$A \beta+$ Simvastatin

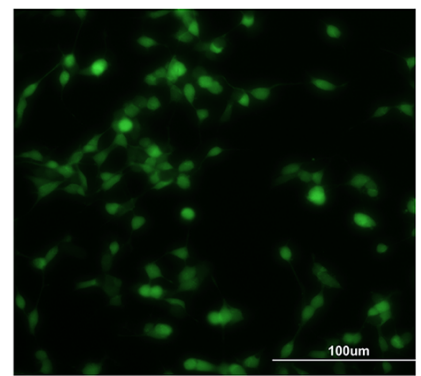

D

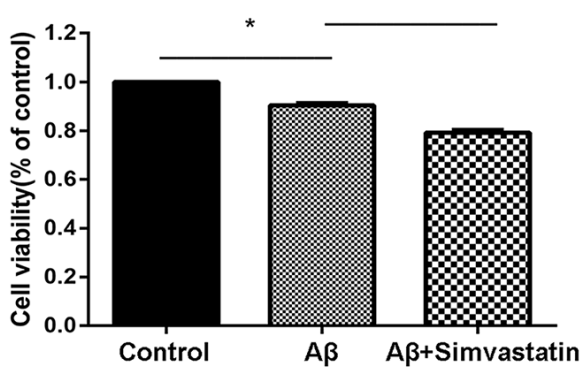

FIGURE 3 | Simvastatin treatment changes the cell morphology and mitochondrial structure, increases the intracellular reactive oxygen species (ROS) level and aggravates the cytotoxic effect of $A \beta_{25-35}$ in SHSY5Y cells. After treated with $10 \mu \mathrm{M}$ simvastatin for $24 \mathrm{~h}$ and $20 \mu \mathrm{M}$ A $\beta_{25-35}$ for $4 \mathrm{~h}$, the morphology of SHSY5Y cells were observed by a light microscope (A), the mitochondrial structures were observed by an electron microscope (B), the intracellular ROS level was measured by DCFH (C), viability of the cells was examined by Cell Counting Kit 8 (CCK8) assay (D). The data are mean \pm SEM $\left(n=3,{ }^{*} p<0.05\right)$. 


\section{A}

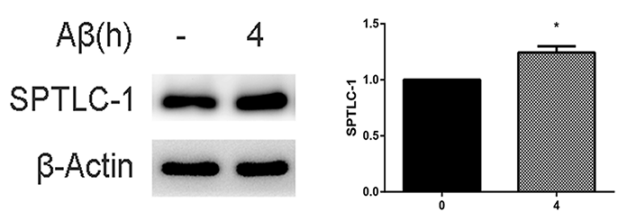

B
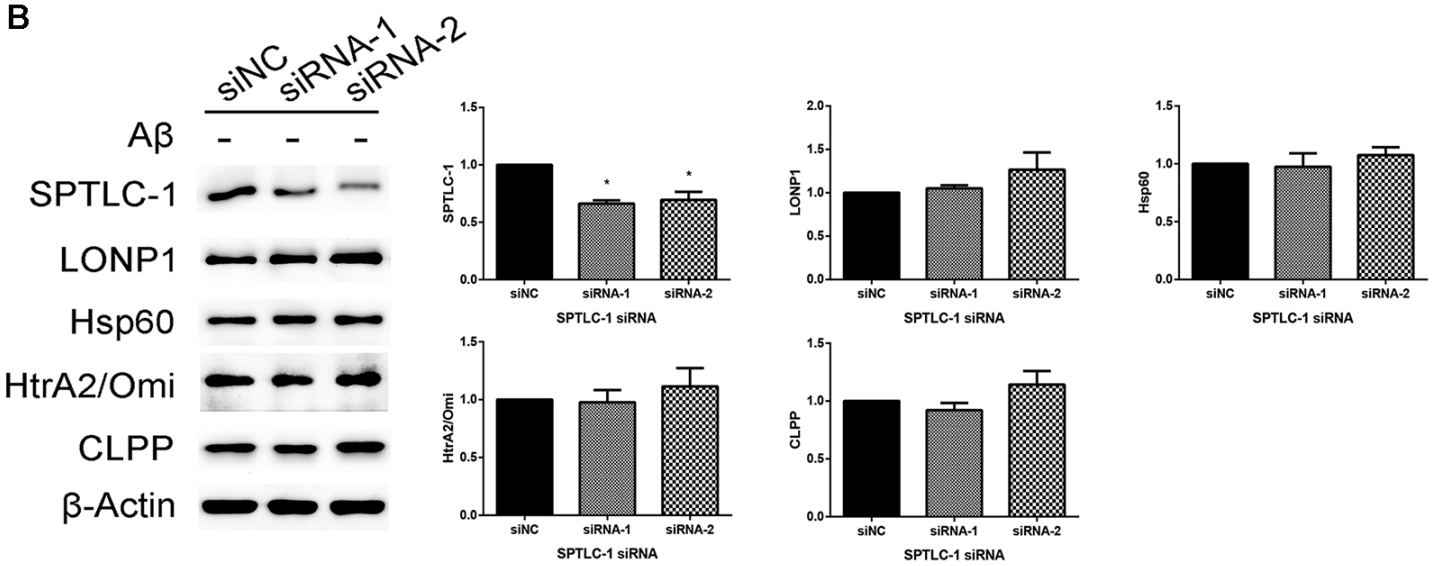

C
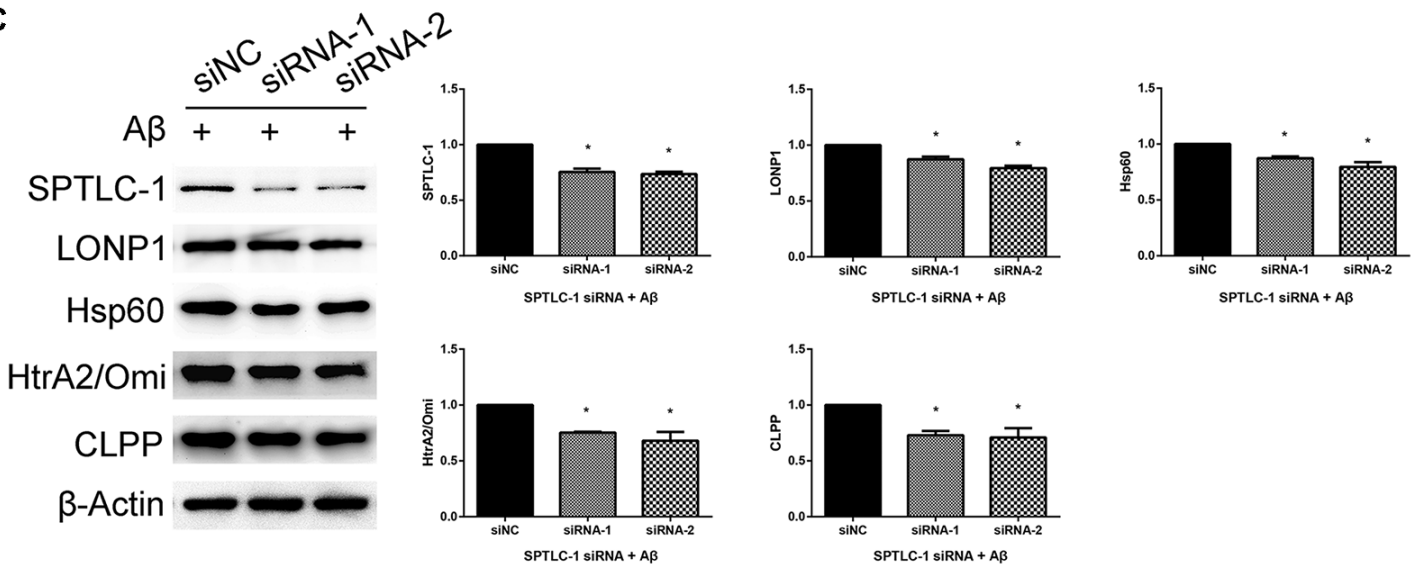

FIGURE 4 | Inhibition of the sphingolipid biosynthesis pathway by serine palmitoyltransferase long chain subunit 1 (SPTLC-1) siRNAs reduces the UPRmt reaction induced by $A \beta_{25-35}$ in SHSY5Y cells. (A) Western blot analysis of SPTLC-1 protein level in SHSY5Y cells treated with $20 \mu \mathrm{M}$ A $\beta_{25-35}$ for $4 \mathrm{~h}$, quantification and $\beta$-Actin served as the internal control. The data are mean \pm SEM ( $n=3,{ }^{*} p<0.05$ vs. control group). (B) Western blot analysis of SPTLC-1 and UPRmt related proteins level in SHSY5Y cells transfected with scramble or SPTLC- 1 siRNAs for $48 \mathrm{~h}$, quantification and $\beta$-Actin served as the internal control. The data are mean \pm SEM $(n=3$, ${ }^{*} p<0.05$ vs. siNC group). (C) Western blot analysis of SPTLC-1 and UPRmt related proteins level in SHSY5Y cells transfected with scramble or SPTLC-1 siRNAs for $48 \mathrm{~h}$ and $20 \mu \mathrm{M} \mathrm{A} \beta_{25-35}$ treatment for $4 \mathrm{~h}$, quantification and $\beta$-Actin served as the internal control. The data are mean $\pm \mathrm{SEM}\left(n=3,{ }^{*} p<0.05 \mathrm{vs}\right.$. siNC group).

after treated the SHSY5Y cell with 2.5 or $5 \mu \mathrm{M} \mathrm{A} \beta_{25-35}$ for $24 \mathrm{~h}$, but increased after 10 or $20 \mu \mathrm{M} \mathrm{A} \beta_{25-35}$ treatment. Combined with the results in the mouse model, the LONP1 protein level was unchanged in APPsw/PS1dE9 transgenic mice at 3 months but increased at 9 months compared with age-matched WT mice. Hence we speculate that the activation of LONP1 protein may need a prolonged or a large dose of $\mathrm{A} \beta$ stimulation, but further research is needed to confirm this. From the result in Figure 1C, we found that the expression levels of Hsp60 and HtrA2/Omi were significantly decreased in the hippocampus of 9 months old APPsw/PS1dE9 transgenic mice relative to those of 3 months old transgenic mice. Compared with age-matched WT mice, the UPRmt related proteins HtrA2/Omi and CLPP were upregulated in APPsw/PS1dE9 transgenic mice at 3 month but unchanged at 9 month, which suggest that the UPRmt activation decreased with age during theAD process. This is consistent with Sorrentino's research that several UPRmt genes were down-regulated in the cortex samples of 9 months old $\mathrm{AD}$ mice compared with those of 
A

control

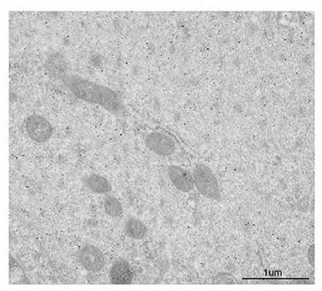

B

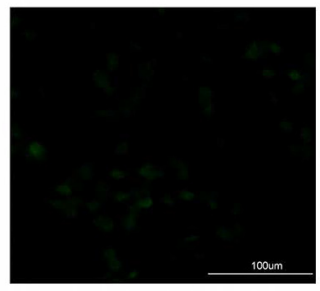

$A \boldsymbol{\beta}$

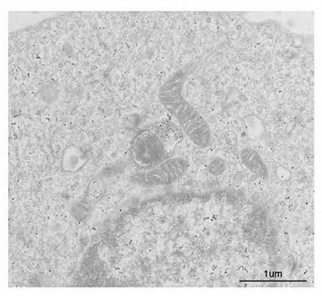

$A \beta$

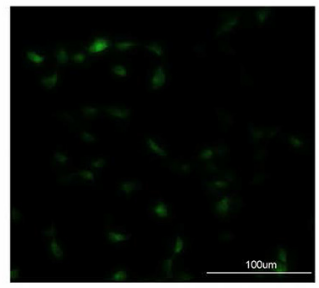

\section{$A \beta+S P T L C-1$ siRNA-1 $A \beta+S P T L C-1$ siRNA-2}
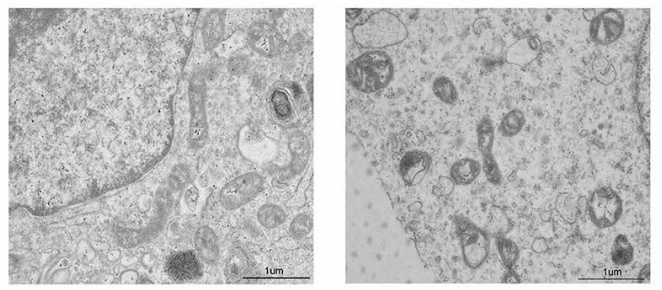

$A \beta+S P T L C-1$ siRNA-1 $A \beta+S P T L C-1$ siRNA-2
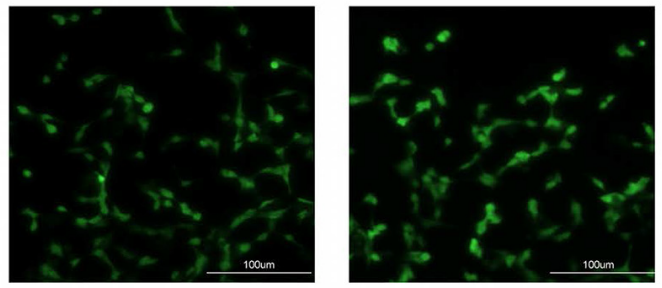

C
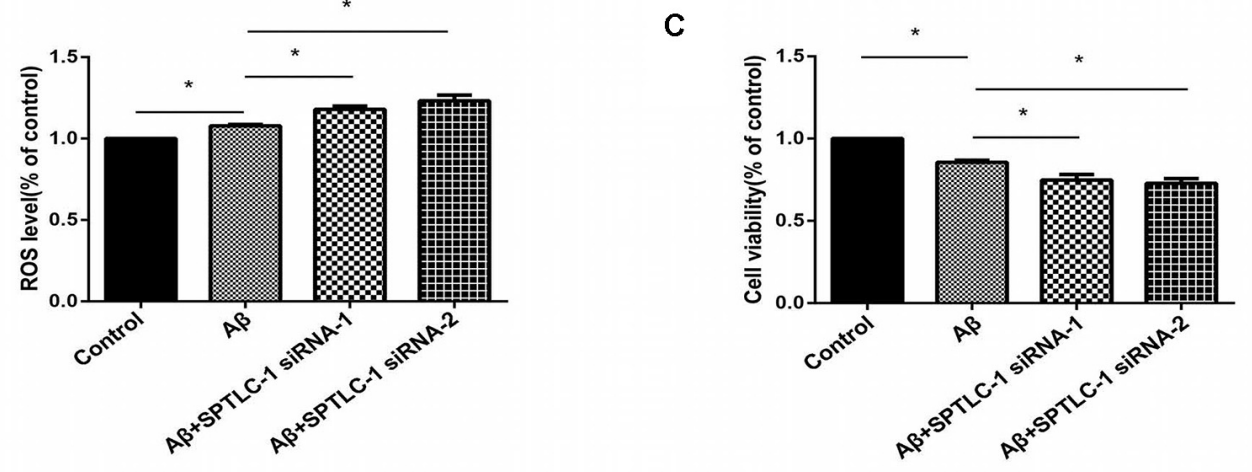

FIGURE 5 | Inhibition of the sphingolipid biosynthesis pathway by SPTLC-1 siRNAs changes the mitochondrial structure, increases the intracellular ROS level and aggravates the cytotoxic effect of $A \beta_{25-35}$ in SHSY5Y cells. After transfected with SPTLC-1 siRNAs for $48 \mathrm{~h}$ and $20 \mu \mathrm{M} A \beta_{25-35}$ for $1 \mathrm{~h}$, the mitochondrial structure of SHSY5Y cells was observed by a electron microscope (A), the intracellular ROS level was measured by DCFH (B), viability of the cells was examined by CCK8 assay (C). The data are mean $\pm \operatorname{SEM}\left(n=3,{ }^{*} p<0.05\right)$.

6 months old AD mice (Sorrentino et al., 2017). Another research about the endoplasmic reticulum UPR response in Down syndrome also found that the UPR was selectively activated at 3 months, but restored to basal controls at 9 months (Lanzillotta et al., 2018). So we conclude that the UPRmt response is activated during the $\mathrm{AD}$ process in mice and cell models, but levels are altered in $\mathrm{AD}$ mice at different time points.

The mevalonate pathway is a key metabolic cascade that catalyzes the synthesis of sterol and nonsterol isoprenoids, which plays important effects on many cellular processes and physiological states (Goldstein and Brown, 1990). The HMG-CoA synthase HMGCS-1 and the HMG-CoA reductase HMGCR mediate this pathway as mentioned above, whereas stains as cholesterol-lowering drugs act by inhibiting the HMGCR. In our study, the HMGCS-1 protein level was increased in SHSY5Y cells after treated with $20 \mu \mathrm{M} \mathrm{A} \beta_{25-35}$ for $4 \mathrm{~h}$, and after inhibiting the mevalonate pathway by HMGCS-1 siRNA or simvastatin in SHSY5Y cells treated with $A \beta_{25-35}$, the expression of UPRmt related proteins were decreased. This is consistent with the researches in C. elegans that the UPRmt upregulates the expression of HMGS-1 (Oks et al., 2018), and inhibition of the mevalonate pathway through the hmgr-1 deletion mutant, hmgs-1 gene inactivation or statins prevents the activation of UPRmt (Liu et al., 2014; Ranji et al., 2014). We also found that inactivation of HMGCS-1 by siRNAs has no effect on the UPRmt reaction in SHSY5Y cells without $\mathrm{A} \beta$ treatment. From the above, our research provides evidence 
that the mevalonate pathway is necessary to the activation of UPRmt induced by $A \beta$ and this effect of the mevalonate pathway was $A \beta$-dependent.

Several reports have revealed a novel connection between the sphingolipid biosynthesis and the endoplasmic reticulum UPR activation (Spassieva et al., 2009; Lépine et al., 2011; Epstein et al., 2012), but none was about the correlations between induction of UPRmt and the ceramide synthesis pathway in AD. As shown in our results, the SPTLC-1 protein level is increased in SHSY5Y cells after treated with $20 \mu \mathrm{M} \mathrm{A} \beta_{25-35}$ for $4 \mathrm{~h}$. Inhibition of the ceramide synthesis by SPTLC-1 siRNA decreased the UPRmt related proteins levels in SHSY5Y cells treated with $\mathrm{A} \beta_{25-35}$ transiently, which provides evidence for an involvement of ceramide synthase SPTLC-1 in the activation of UPRmt response in $\mathrm{AD}$ cell models. The result is consistent with the researches in C. elegans that the UPRmt upregulates the transcript level of sptl-1, and inhibition of the sphingolipid biosynthesis pathway through the sptl-1 gene inactivation prevents the activation of UPRmt (Liu et al., 2014). Ceramide, which is the core structure of all complex sphingolipids, serves as the second messenger that regulates diverse cellular processes such as growth, differentiation, and apoptosis (Pettus et al., 2002). Ceramide levels can be reduced by inhibition of SPT both in vitro and in vivo (Hojjati et al., 2005; Holland et al., 2007). It have been proved that ceramide levels were increased at the earliest stage during the $\mathrm{AD}$ process (Han et al., 2002; Katsel et al., 2007; Mielke et al., 2010). Studies in patients with sporadic $\mathrm{AD}$ also showed that the levels of ceramide and SPT protein including SPTLC-1 were significantly elevated compared with control (Geekiyanage and Chan, 2011). SPT activity has proved increasing in dealing with various stimuli in cell research (Perry et al., 2000; Scarlatti et al., 2003). We also found that inactivation of SPTLC-1 by siRNAs has no effect on the UPRmt reaction in SHSY5Y cells without $\mathrm{A} \beta$ treatment. Thus, we conclude that $A \beta_{25-35}$ treatment increases the protein levels of SPTLC-1, and the sphingolipid biosynthesis pathway is necessary to the activation of UPRmt induced by $A \beta$ and this effect of the mevalonate pathway was $\mathrm{A} \beta$-dependent.

As shown in our results, inhibition of the mevalonate pathway or the sphingolipid biosynthesis pathway can prevent the activation of UPRmt, change the mitochondrial structure, increase the intracellular ROS level and aggravate the cytotoxic effect of $A \beta_{25-35}$ in SHSY5Y cells, which suggest that the UPRmt can protect SHSY5Y cells from the damage of $A \beta_{25-35}$. The UPRmt has been proved cytoprotective effects in several reports (Baker et al., 2012; Runkel et al., 2013; Lamech and Haynes, 2015), and activation of the UPRmt response can also extend lifespan (Durieux et al., 2011; Houtkooper et al., 2013). Therefore, our research provides new evidence for the UPRmt

\section{REFERENCES}

Baker, B. M., Nargund, A. M., Sun, T., and Haynes, C. M. (2012). Protective coupling of mitochondrial function and protein synthesis via the eIF2 $\alpha$ kinase GCN-2. PLoS Genet. 8:e1002760. doi: 10.1371/journal.pgen.1002760 cytoprotective effect during the $\mathrm{AD}$ process. It also provides a new sight for us whether enhancing or artificial activation of UPRmt can protect cells from the cytotoxic effect of $A \beta$ and works on the treatment of $\mathrm{AD}$. But several reports have revealed that the prolonged or over activation of the UPRmt has an adverse effect like shortening the lifespan of C. elegans (Bennett et al., 2014), perturb mitochondrial function (Lamech and Haynes, 2015; Lin et al., 2016). So further research is needed on whether enhanced UPRmt activation can be used in the treatment of $\mathrm{AD}$ because the intensity and duration of the response should be considered.

Together, these observations imply that the UPRmt activated in $\mathrm{AD}$ cell and mice models, but the levels vary according to the ages of mice. We further observed that the mevalonate and sphingolipid biosynthesis pathways were necessary for the activation of UPRmt in AD. When inhibiting the two pathways, the cytotoxic effects of $A \beta_{25-35}$ in SHSY5Y cells were aggravated. Hence our research helps us understanding the role of UPRmt in the pathogenesis of $\mathrm{AD}$, which may provide new sights for the treatment of $\mathrm{AD}$.

\section{DATA AVAILABILITY STATEMENT}

All datasets generated for this study are included in the article.

\section{ETHICS STATEMENT}

The animal study was reviewed and approved by the Ethical Committee for Animal Experiments of the Second Hospital of Shandong University.

\section{AUTHOR CONTRIBUTIONS}

JB, PW, and YS designed the research. YS performed the experiments. MD, ZX, and XL provided technical support and helped with mouse dissections. HY, SJ, SX, ZZ, YW, DW, LX, and $\mathrm{XZ}$ analyzed the data. JB, PW, and YS wrote the manuscript. All authors read and approved the final manuscript.

\section{FUNDING}

This work was supported by National Natural Science Foundation of China (Grant Nos. 81571052, 81870848 and 81401052), The Fundamental Research Funds of Chinese Academy of Medical Sciences (Grant No. 2019-RC-HL-026), the Key Research and Development Program of Shandong Province (Grant Nos. 2015GSF118056, 2017GSF218036 and 2017GSF218046) and The Fundamental Research Funds of Shandong University (Grant No. 2016JC022). 
does not predict longevity in Caenorhabditis elegans. Nat. Commun. 5:3483. doi: $10.1038 /$ ncomms 4483

Blackstone, N. W. (2015). The impact of mitochondrial endosymbiosis on the evolution of calcium signaling. Cell Calcium 57, 133-139. doi: 10.1016/j.ceca. 2014.11.006

Borchelt, D. R., Thinakaran, G., Eckman, C. B., Lee, M. K., Davenport, F., Ratovitsky, T., et al. (1996). Familial Alzheimer's disease-linked presenilin 1 variants elevate $\mathrm{A} \beta 1-42 / 1-40$ ratio in vitro and in vivo. Neuron 17 , 1005-1013. doi: 10.1016/s0896-6273(00)80230-5

Caspersen, C., Wang, N., Yao, J., Sosunov, A., Chen, X., Lustbader, J. W., et al. (2005). Mitochondrial $A \beta$ : a potential focal point for neuronal metabolic dysfunction in Alzheimer's disease. FASEB J. 19, 2040-2041. doi: 10.1096/fj. 05-3735fje

Da Costa Dias, B., Jovanovic, K., Gonsalves, D., and Weiss, S. F. (2011). Structural and mechanistic commonalities of amyloid- $\beta$ and the prion protein. Prion 5 , 126-137. doi: 10.4161/pri.5.3.17025

Durieux, J., Wolff, S., and Dillin, A. (2011). The cell-non-autonomous nature of electron transport chain-mediated longevity. Cell 144, 79-91. doi: 10.1016/j. cell.2010.12.016

Epstein, S., Kirkpatrick, C. L., Castillon, G. A., Muniz, M., Riezman, I., David, F. P., et al. (2012). Activation of the unfolded protein response pathway causes ceramide accumulation in yeast and INS-1E insulinoma cells. J. Lipid Res. 53, 412-420. doi: 10.1194/jlr.m022186

Geekiyanage, H., and Chan, C. (2011). MicroRNA-137/181c regulates serine palmitoyltransferase and in turn amyloid $\beta$, novel targets in sporadic Alzheimer's disease. J. Neurosci. 31, 14820-14830. doi: 10.1523/jneurosci.388311.2011

Goldstein, J. L., and Brown, M. S. (1990). Regulation of the mevalonate pathway. Nature 343, 425-430. doi: 10.1038/343425a0

Han, X., Holtzman, D. M., Mckeel, D. W. Jr., Kelley, J., and Morris, J. C. (2002). Substantial sulfatide deficiency and ceramide elevation in very early Alzheimer's disease: potential role in disease pathogenesis. J. Neurochem. 82, 809-818. doi: 10.1046/j.1471-4159.2002.00997.x

Hanada, K. (2003). Serine palmitoyltransferase, a key enzyme of sphingolipid metabolism. Biochim. Biophys. Acta 1632, 16-30. doi: 10.1016/s13881981(03)00059-3

Harkany, T., Abraham, I., Timmerman, W., Laskay, G., Toth, B., Sasvari, M., et al. (2000). $\beta$-amyloid neurotoxicity is mediated by a glutamate-triggered excitotoxic cascade in rat nucleus basalis. Eur. J. Neurosci. 12, 2735-2745. doi: 10.1046/j.1460-9568.2000.00164.x

Haynes, C. M., and Ron, D. (2010). The mitochondrial UPR-protecting organelle protein homeostasis. J. Cell Sci. 123, 3849-3855. doi: 10.1242/jcs. 075119

Hojjati, M. R., Li, Z., Zhou, H., Tang, S., Huan, C., Ooi, E., et al. (2005). Effect of myriocin on plasma sphingolipid metabolism and atherosclerosis in apoE-deficient mice. J. Biol. Chem. 280, 10284-10289. doi: 10.1074/jbc. $\mathrm{m} 412348200$

Holland, W. L., Brozinick, J. T., Wang, L. P., Hawkins, E. D., Sargent, K. M., Liu, Y., et al. (2007). Inhibition of ceramide synthesis ameliorates glucocorticoid-, saturated-fat- and obesity-induced insulin resistance. Cell Metab. 5, 167-179. doi: 10.1016/j.cmet.2007.01.002

Hornemann, T., Richard, S., Rutti, M. F., Wei, Y., and Von Eckardstein, A. (2006). Cloning and initial characterization of a new subunit for mammalian serine-palmitoyltransferase. J. Biol. Chem. 281, 37275-37281. doi: 10.1074/jbc. m608066200

Hornemann, T., Wei, Y., and von Eckardstein, A. (2007). Is the mammalian serine palmitoyltransferase a high-molecular-mass complex? Biochem. J. 405, 157-164. doi: 10.1042/bj20070025

Houtkooper, R. H., Mouchiroud, L., Ryu, D., Moullan, N., Katsyuba, E., Knott, G., et al. (2013). Mitonuclear protein imbalance as a conserved longevity mechanism. Nature 497, 451-457. doi: 10.1038/nature 12188

Kang, J., Lemaire, H. G., Unterbeck, A., Salbaum, J. M., Masters, C. L., Grzeschik, K. H., et al. (1987). The precursor of Alzheimer's disease amyloid A4 protein resembles a cell-surface receptor. Nature 325, 733-736. doi: 10.1038/325733a0

Katsel, P., Li, C., and andHaroutunian, V. (2007). Gene expression alterations in the sphingolipid metabolism pathways during progression of dementia and Alzheimer's disease: a shift toward ceramide accumulation at the earliest recognizable stages of Alzheimer's disease? Neurochem. Res. 32, 845-856. doi: 10.1007/s11064-007-9297-x

Lamech, L. T., and Haynes, C. M. (2015). The unpredictability of prolonged activation of stress response pathways. J. Cell Biol. 209, 781-787. doi: $10.1083 /$ jcb. 201503107

Lanzillotta, C., Tramutola, A., Meier, S., Schmitt, F., Barone, E., Perluigi, M., et al. (2018). Early and selective activation and subsequent alterations to the unfolded protein response in down syndrome mouse models. J. Alzheimers Dis. 62, 347-359. doi: 10.3233/jad-170617

Lépine, S., Allegood, J. C., Park, M., Dent, P., Milstien, S., and Spiegel, S. (2011). Sphingosine-1-phosphate phosphohydrolase-1 regulates ER stressinduced autophagy. Cell Death Differ. 18, 350-361. doi: 10.1038/cdd. 2010.104

Lin, Y. F., Schulz, A. M., Pellegrino, M. W., Lu, Y., Shaham, S., and Haynes, C. M. (2016). Maintenance and propagation of a deleterious mitochondrial genome by the mitochondrial unfolded protein response. Nature 533, 416-419. doi: 10.1038/nature17989

Liu, Y., Samuel, B. S., Breen, P. C., and Ruvkun, G. (2014). Caenorhabditis elegans pathways that surveil and defend mitochondria. Nature 508, 406-410. doi: 10.1038 /nature13204

Lustbader, J. W., Cirilli, M., Lin, C., Xu, H. W., Takuma, K., Wang, N., et al. (2004). $\mathrm{ABAD}$ directly links $\mathrm{A} \beta$ to mitochondrial toxicity in Alzheimer's disease. Science 304, 448-452. doi: 10.1126/science.1091230

Manczak, M., Anekonda, T. S., Henson, E., Park, B. S., Quinn, J., and Reddy, P. H. (2006). Mitochondria are a direct site of $\mathrm{A} \beta$ accumulation in Alzheimer's disease neurons: implications for free radical generation and oxidative damage in disease progression. Hum. Mol. Genet. 15, 1437-1449. doi: $10.1093 / \mathrm{hmg} / \mathrm{ddl} 066$

Mielke, M. M., Bandaru, V. V., Haughey, N. J., Rabins, P. V., Lyketsos, C. G., and Carlson, M. C. (2010). Serum sphingomyelins and ceramides are early predictors of memory impairment. Neurobiol. Aging 31, 17-24. doi: 10.1016/j. neurobiolaging.2008.03.011

Mielke, M. M., and Haughey, N. J. (2012). Could plasma sphingolipids be diagnostic or prognostic biomarkers for Alzheimer's disease? Clin. Lipidol. 7, 525-536. doi: 10.2217/clp.12.59

Oks, O., Lewin, S., Goncalves, I. L., and Sapir, A. (2018). The UPR ${ }^{m t}$ protects Caenorhabditis elegans from mitochondrial dysfunction by upregulating specific enzymes of the mevalonate pathway. Genetics 209, 457-473. doi: 10.1534/genetics.118.300863

Papa, L., and Germain, D. (2011). Estrogen receptor mediates a distinct mitochondrial unfolded protein response. J. Cell Sci. 124, 1396-1402. doi: $10.1242 /$ jcs. 078220

Pellegrino, M. W., Nargund, A. M., and Haynes, C. M. (2013). Signaling the mitochondrial unfolded protein response. Biochim. Biophys. Acta 1833, 410-416. doi: 10.1016/j.bbamcr.2012.02.019

Perry, D. K., Carton, J., Shah, A. K., Meredith, F., Uhlinger, D. J., and Hannun, Y. A. (2000). Serine palmitoyltransferase regulates de novo ceramide generation during etoposide-induced apoptosis. J. Biol. Chem. 275, 9078-9084. doi: $10.1074 /$ jbc.275.12.9078

Pettus, B. J., Chalfant, C. E., and Hannun, Y. A. (2002). Ceramide in apoptosis: an overview and current perspectives. Biochim. Biophys. Acta 1585, 114-125. doi: 10.1016/s1388-1981(02)00331-1

Pleckaityte, M. (2010). [Alzheimer's disease: a molecular mechanism, new hypotheses and therapeutic strategies]. Medicina 46, 70-76. doi: 10.3390/medicina46010011

Ranji, P., Rauthan, M., Pitot, C., and Pilon, M. (2014). Loss of HMG-CoA reductase in $C$. elegans causes defects in protein prenylation and muscle mitochondria. PLoS One 9:e100033. doi: 10.1371/journal.pone.0100033

Runkel, E. D., Liu, S., Baumeister, R., and Schulze, E. (2013). Surveillance-activated defenses block the ROS-induced mitochondrial unfolded protein response. PLoS Genet. 9:e1003346. doi: 10.1371/journal.pgen.1003346

Sapir, A., Tsur, A., Koorman, T., Ching, K., Mishra, P., Bardenheier, A., et al. (2014). Controlled sumoylation of the mevalonate pathway enzyme HMGS-1 regulates metabolism during aging. Proc. Natl. Acad. Sci. U S A 111, E3880-E3889. doi: 10.1073/pnas.1414748111

Scarlatti, F., Sala, G., Somenzi, G., Signorelli, P., Sacchi, N., and Ghidoni, R. (2003). Resveratrol induces growth inhibition and apoptosis in metastatic breast cancer 
cells via de novo ceramide signaling. FASEB J. 17, 2339-2341. doi: 10.1096/fj. 03-0292fje

Selkoe, D. J. (2001). Alzheimer's disease: genes, proteins, and therapy. Physiol. Rev. 81, 741-766. doi: 10.1152/physrev.2001.81.2.741

Skovronsky, D. M., Lee, V. M., and Trojanowski, J. Q. (2006). Neurodegenerative diseases: new concepts of pathogenesis and their therapeutic implications. Annu. Rev. Pathol. 1, 151-170. doi: 10.1146/annurev.pathol.1.110304.100113

Sorrentino, V., Romani, M., Mouchiroud, L., Beck, J. S., Zhang, H., D’Amico, D., et al. (2017). Enhancing mitochondrial proteostasis reduces amyloid- $\beta$ proteotoxicity. Nature 552, 187-193. doi: 10.1038/nature25143

Spassieva, S. D., Mullen, T. D., Townsend, D. M., and Obeid, L. M. (2009). Disruption of ceramide synthesis by CerS2 down-regulation leads to autophagy and the unfolded protein response. Biochem. J. 424, 273-283. doi: 10.1042/bj20090699

Spiegel, S., and Merrill, A. H. Jr. (1996). Sphingolipid metabolism and cell growth regulation. FASEB J. 10, 1388-1397. doi: 10.1096/fasebj.10.12.8903509

Swerdlow, R. H. (2007). Pathogenesis of Alzheimer's disease. Clin. Interv. Aging 2, 347-359.

Tatsuta, T., and Langer, T. (2008). Quality control of mitochondria: protection against neurodegeneration and ageing. EMBO J. 27, 306-314. doi: 10.1038/sj. emboj.7601972
Wang, C., and Youle, R. J. (2009). The role of mitochondria in apoptosis*. Annu. Rev. Genet. 43, 95-118. doi: 10.1146/annurev-genet-102108-134850

Westerlund, M., Behbahani, H., Gellhaar, S., Forsell, C., Belin, A. C., Anvret, A., et al. (2011). Altered enzymatic activity and allele frequency of OMI/HTRA2 in Alzheimer's disease. FASEB J. 25, 1345-1352. doi: 10.1096/fj.10163402

Zhao, Q., Wang, J., Levichkin, I. V., Stasinopoulos, S., Ryan, M. T., and Hoogenraad, N. J. (2002). A mitochondrial specific stress response in mammalian cells. EMBO J. 21, 4411-4419. doi: 10.1093/emboj/cdf445

Conflict of Interest: The authors declare that the research was conducted in the absence of any commercial or financial relationships that could be construed as a potential conflict of interest.

Copyright (C) 2020 Shen, Ding, Xie, Liu, Yang, Jin, Xu, Zhu, Wang, Wang, Xu, Zhou, Wang and Bi. This is an open-access article distributed under the terms of the Creative Commons Attribution License (CC BY). The use, distribution or reproduction in other forums is permitted, provided the original author(s) and the copyright owner(s) are credited and that the original publication in this journal is cited, in accordance with accepted academic practice. No use, distribution or reproduction is permitted which does not comply with these terms. 